\title{
Constructivist Approach to the Problem of Social Psychological Adaptation of Migrants
}

\author{
Efremova Galina Ivanovna ${ }^{1}$, Nesterova Albina Alexandrovna ${ }^{1}$, Suslova Tatjana Fedorovna ${ }^{1} \&$ Pavlova Olga \\ Evgenyevna ${ }^{1}$ \\ 1 "The North Caucasus Federal University", Russia \\ Correspondence: Efremova Galina Ivanovna, "The North Caucasus Federal University", Pushkina st. 1, \\ Stavropol 355009, Russia. E-mail: efremova_ncfu@mail.ru
}

Received: September 17, 2014 Accepted: October 9, 2014 Online Published: December 2, 2014

doi:10.5539/ass.v11n1p112

URL: http://dx.doi.org/10.5539/ass.v11n1p112

\begin{abstract}
This article analyzes the problem of migration, research on the social psychological adaptation of migrants in the Russian and foreign psychology, different approaches developed in the paradigm of constructivism are shown. Directions of research on adaptation of migrants that are relevant to the purpose of determining the possibilities of using the constructivist approach in addressing adaptation of migrants to the new social environment are presented. The features that are common to all constructivist approaches that characterize the possibility of using a constructive approach in social psychological support of migrants in adapting to the new environment are allocated.
\end{abstract}

Keywords: constructivism, constructivist approach in psychology, constructivist approach to the adaptation of the person, migration, migrant, social psychological adaptation

\section{Introduction}

The problem of social psychological adaptation, studying the main factors that facilitate and impede migrants' adaptation to different socio-cultural environment, search for appropriate technologies of adaptation of migrants are currently relevant in many countries around the world. According to the International Organization for Migration, the number of international migrants around the world in 2013 was about 232 million people. If the migration will continue to increase at the same rate as it did over the past 20 years, international migration in 2050 will have more than 400 million people. Economic competition and related fears, as well as ethnic and religious xenophobia lead to discrimination against migrants. There are problems not only for the communities around the world, but also for the migrants themselves in terms of their adaptation to an unfamiliar and often alien culture, to economic and political systems (Rerkins, Palmer, \& García-Ramírez, 2011).

In recent decades, migration has appeared in a number of the world's major problems. Migration processes have reached unprecedented proportions. In terms of migration Russia is in third place after Germany and the United States, taking an average of 781 thousands of migrants per year (Bauer, 2012). There is a high percentage of citizens of the former Soviet republics of Uzbekistan, Kyrgyzstan, Tajikistan, Moldova, and others moving to Russia, with a purpose of either a change of residence, or, more often, temporary employment (the so-called migrant workers). The number of migrants, although in small amounts, is replenished by citizens of EU countries, as well as Asia and the Arab countries.

In situation of migration a man is faced with various problems: problems of social and domestic arrangement, job search; need of learning the language, legal, moral, social and cultural norms. Difficulties occur in adopting values and behaviors inherent in the new environment. There are certain difficulties in establishing the interaction with others, both in business and interpersonal contact. Getting into a new socio-cultural environment complicates the process of adoption of the migrant status new to themselves, and it complicates the need of re-adaptation as well, namely the revision of the former, usual forms of interaction with environment and search for new ones. All this has its own specifics in a situation of migration and influences the person as a whole, thereby creating difficulties in the manifestation of vitality, personal potential, own identity. In a situation of adaptation to the conditions of the new environment, mismatch in values and social norms, general is satisfaction with functioning in various spheres of life can be formed among migrants, which inevitably leads to a powerful 
stress situation. Thus, organization of the process of social psychological adaptation of migrants is relevant for Russia today.

In Russian science and practice a wealth of research and applied experience on issue of migrants and migration is accumulated. Centers and university laboratories on problems of migration and provision of various forms of assistance to migrants, created in every region of Russia, are working successfully, conducting deep theoretical and empirical research. In Moscow alone, Laboratory of analysis and forecasting of migration of the Institute of Economic Forecasting of the Russian Academy of Sciences (RAS), Laboratory for Migration Studies, Institute for Socio-Economic Studies of Population, Center for Migration Studies, Migration Museum, Centre for Social psychological adaptation and rehabilitation of the refugees of the Russian Red cross and others are all engaged in problems of migration and migrants. Media make their own contribution - magazines "Ethno-world", "Ethno-dialogs", "Migration XXI Century", "Moscow nations," etc.

\section{Research on the Social Psychological Adaptation of Migrants Abroad}

The problem of positive social adaptation of migrants is being actively discussed in foreign studies. Scientists from the Netherlands and North Carolina - G. Grënevold, Bart de Bruijn and R. Bilsborrow believe that psychosocial factors that influence the behavior and adaptation of migrants are not studied enough currently in migration studies. In medical research, in contrast to the social theories of migration, beliefs, intentions, attitudes, and personality factors are often in focus. Three theories are mainly used in health sector in order to explain human behavior: social cognitive theory of Albert Bandura, theory of rational behavior of M. Fishbein and I. Ajzen and model of healthy behavior - Health Belief Model (HBM). G. Grënevold, Bart de Bruijn and R. Bilsborrow took model of healthy behavior as a basis, integrating it with social cognitive theory and the theory of rational behavior, creating a model of psychosocial behavior of migrants. The idea of dynamic interaction between human behavior, his personal characteristics and the environment, the idea that individuals with high self-esteem have much clearer aspirations, put more effort in selecting targets and more persistence in overcoming difficulties and failures are taken from the theory of Bandura A. The idea of understanding the intentions as predictors of behavior was taken by the authors from the theory of rational behavior. Intentions, according to this theory, are defined by a man's representations. Thereafter, behavior can be changed by effecting the belief system. Five factors were identified in psycho-social model of behavior of migrants: (1) perception of threat to living conditions (dissatisfaction with domestic and financial position); (2) anticipated benefits of migration; (3) possible migration barriers (religion, finding a paid job); (4) events that trigger migration (calls to action) - motivation, personality and interpersonal relationships; (5) self-confidence (self-sufficiency) understanding that life can be changed, planned, monitored.The authors believe that this model will help to better understand the intentions and decision-making strategies of migrants, possibilities of their social psychological adaptation, thus expanding the basis for an optimal migration policy (Groenewold, de Bruijn, \& Bilsborrow, 2012).

Samantha Perrin (2012) studied the effects of meritocratic beliefs of migrants from North Africa who migrated to France, the ability to integrate into Western society. According to the author's studies, social psychological adaptation was more successful among migrants with a belief that in a society in the course of evolution the principle of promotion of the most capable people, selected from all social strata, to senior positions has established. Such people adopted the culture of a host country and built personal relationships with people of this country more easily (Perrin, 2012). Thus, the influence of social attitudes and beliefs of migrants on the success of their adaptation was proved.

Connection between strategies of acculturation and psychological adaptation of Russian and German migrants in New Zealand, Turkish migrants in the UK, the Muslim migrants in the Netherlands, Filipino migrant workers in Hong Kong, Latin American migrants in the United States was studied by J.W .Berry (2001); E. Maydell-Stevens, A. Masgoret, T. Ward (2007), M. van Geel, P. Vedder (2010); S. Gulfem Cakir, Oya Yerin Guneri (2011) and others.

Socio-cultural adaptation reflects the ability of constructive engagement with a different culture. There are four different strategies of acculturation, which can be used by migrants: (1) separation, (2) assimilation, (3) integration, and (4) marginalization. The strategy of separation includes migrants' maintaining the culture of origin and rejection of the culture of settlement. Assimilation is a strategy in which a person refuses an ethnic heritage and replaces it with a new acquired cultural identity. Integration means saving a man's cultural heritage, together with acquisition of some features of the host culture, while the adoption of a marginalization strategy constitute a man's waiver of both culture of the settlement, and culture of origin (Berry, 2001). 
Studies have consistently shown that the integration strategy is yielding positive results in social psychological adaptation of migrants. Study participants experienced high levels of psychological stress in the initial stage of their resettlement, but those who later chose integration as a strategy of acculturation were more successful and adaptable. Upon successful psychological adaptation an individual feels a sense of well-being, positively assesses current situation, and is generally satisfied with life. Three other strategies, and especially the marginalization, are associated with negative adaptation, which can lead to serious psychological disorders, including depression, anxiety and other psychological problems (Aroian, 1990), Maydell-Stevens E., Masgoret A., Ward T. (2007).

The study of adaptation of Turkish women who emigrated to the UK, showed that such strategies of acculturation as separation, assimilation and marginalization, reduce psychological adaptation, while social support and integration strategies provide empowerment of migrant women (Cakir \& Guneri, 2011).

There are a small number of studies carried out by foreign scientists in the framework of constructivism. These studies show that culture, enshrined in form of cognitive schemes, values systems, and social representations forms human behavior. A special role in this process is played by cognitive processes (Rogoff, 2003), emotions (White, 2010) and identity (Shweder \& Sullivan, 1993). Cognitive schemes, social representations, cultural stereotypes are affecting human social behavior so strongly that they even affect the structure, the choice of methods and results of studies of psychological effects of migration, conducted by scientists, who also belong to different cultures and are influenced by their own social attitudes and stereotypes (American Psychological Association, 2002). Therefore, one should carefully select appropriate research methods, consider the process of migration through the prism of cultural features, building of a new social reality by migrants.

Webster and Kruglanski introduced the term Need for Cognitive Closure. NCC, according to the authors, is expressed in five characteristics: (1) desire for order and structure; (2) intolerance of ambiguity; (3) determination in own judgments; (4) desire for stability and predictability; (5) desire for closeness of viewpoints and attitudes, intolerance of differences. This concept is widely used in studies of adaptation of migrants (Kruglanski \& Webster, 1996).

It was proved that the adaptation of migrants to the culture of settlement is just determined by the level of expression of NCC (the need for cognitive closure) and is dependent on their social environment. If, upon arrival at the new place of residence, their own ethnic group (ethnic group of origin) becomes referential for migrants, then with high level of NCC (need for cognitive closure) they will stick to the culture of origin and are will poorly integrate into the new culture.

If a group of new culture representatives will become referential for migrants then the NCC (need for cognitive closure) will increase, and migrants will quickly integrate into a new culture. Thus, referential groups serve as 'providers' of a new culture for migrants, acting through a mechanism of the need for cognitive closure (NCC) (Kruglanski \& Webster, 1996). Using the knowledge about the features of the migrants' need for finality, conditions for the formation of their positive social attitudes can be created to help them to adapt and integrate into a new culture.

\section{Theoretical and Methodological Basics of the Study of Social Psychological Adaptation of Migrants in Russia}

According to psychologists, social psychological adaptation of migrants to the new conditions of life is a complex, multi-faceted and often lengthy process. Its successfulness is in improving the meaningfulness of life, in formation of appropriate behaviors, sustainable positive attitude towards themselves and the world around them, as well as in occurrence of subjective feelings of satisfaction by social relationships, work and life in general (Bauer, Lebedeva, Konstantinov et al.).

In Russian psychology the study of adaptive processes has a long tradition. In the works of I.P. Pavlov we can find the understanding of essence of the process of social adaptation of an individual to an environment. Studies of problem of adaptation of individual to different living conditions were carried out in context of the cultural-historical approach (L. S. Vygotsky), the activity approach (Davydov, Leontiev et al.).

The largest number of theoretical and empirical research in Russia is devoted to the studies of personality tolerance problems, which were carried out in context of intercultural communication. These are the works of A. G. Asmolov, V. V. Boyko, I. B. Grinshpun, E. Yu. Klykova, N. M. Lebedeva, G. U. Soldatova, L. A. Shaygerova, E. I. Shlyagina et al. Overall conclusion of the research can be described as follows: tolerance is a moral quality of a person, which can be described as constructive interaction with individuals and groups that differ by any signs; building relationships with people and social communities in spirit of peace, sufferance, 
humane interpersonal communication; respect for others regardless of their nationality or religion; comprehension of their culture and willingness to integrate into the culture of other nations.

Problem of the influence of migration on psychological characteristics and states of personality of migrants is in active development (Asmolov, Gritsenko, Konstantinov, Soldatova, Shaygerova et al.). It was not our task in this article to consider the results of the research, they are quite extensive and unique, but for our purposes, we consider it important to bring up some of them. They relate to the conclusions made at different times by scientists and practitioners G. U. Soldatova and L. A. Shaygerova. In particular, they note that the migration situation radically changes the whole structure of motives and needs of migrants, which are important regulators of human behavior, makes it difficult to meet the needs of different levels - from the most pressing to the highest (self-esteem and self-actualization) (Soldatova \& Shaygerova, 1994). The authors note the presence of high levels of stress as defining feature of migrants' state. Migrants' psyche is traumatized as by forced departure and by complex process of adaptation to the new location. Scientists say that migrants are in a state of post-traumatic stress. Finally, the study of identity. G. U. Soldatova and L. A. Shaygerova note that forced migrants have an identity crisis. It occurs as a result of events related to the causes of migration and because of culture shock and adaptation in the new environment. As a result of events they are experiencing the very foundation of identity is destroyed - the transformation of the image of the world occurs, which is formed from birth and includes a wide range of images, ideas, opinions, beliefs, attitudes - from the sounds, smells, climate, nature, native language, customs and traditions, family and work relationships to the awareness of being a citizen of a particular country (Soldatova \& Shaygerova, 2002).

The works of interest are those in which the types of social psychological adaptation and severity of psychological characteristics of a subject and their relationship with each other are distinguished, causing the specificity of the social psychological adaptation of migrants (Konstantinov, 2010). In his study, V. V. Konstantinov allocated 6 types of social psychological adaptation: adaptive, conformal, interactive, depressive, nostalgic, alienated. The most common among migrants are adaptive, conformal and interactive, the other three are met much rarer (Konstantinov, 2012). Type of adaptation of migrants and severity of psychological characteristics of the subject and their relationship with each other determines the specificity of the adaptation process of migrants to a new socio-cultural environment. Thus, representatives of adaptive, interactive and conformal types exhibit positive acculturation strategies (separation, assimilation), which contributes significantly to the positive trend of social psychological adaptation. Depressive, nostalgic and alienated migrants tend to marginalization and separation, which is detrimental to the process of entering into a new socio-cultural environment (Konstantinov, 2012).

Specificity and main directions of psychological, psychotherapeutic help for migrants in framework of social and psychological support, individual and group psychotherapy, psychological counseling are reflected in the works of O. V. Barkanova, E. A. Bauer, V. V. Gritsenko, V. K. Kalinenko, N. I. Kovaleva, V. V. Konstantinov, V. N. Pavlenko, A. B. Panteleeva, G. U. Soldatova, M. Yu. O. E Khukhlaev, Chibisova, L. A. Shaygerova and others. They presented the program of social psychological and socio-cultural training, psycho-pedagogical support for migrants, emergent psychological assistance, counseling and psychological help for migrants and members of their families. At the core of these programs is an ideology, technologies and techniques of humanistic, positive, socio-cultural, systemic, psycho-social, integrative, social psychological, and other approaches. However, from our point of view, actively growing in recent years in Russia and abroad constructivist approach can be relevant for the purposes of research practice, practice, social psychological support for migrants, to assist them in resolving emerging problems.

\section{Discussion (Possibilities of Application of Constructivist Approach to the Theory and Practice of Psychology of Migration and Migrants)}

Based on the foregoing and while identifying the opportunities of constructivist approach to the study of social psychological adaptation of migrants and assisting them, it should be noted that migration from a psychological standpoint requires a person of hard work: self-correction and self-change of their own attitudes, the creation of new systems of social representations, changing mental maps, environmental loads, constituting the worlds picture of each individual and determining its social behavior and individual way of construction of social reality, creating more adaptive structures that describe the world in which a man lives and his place in it.

According to I.T. Kasavin, the term "constructivism" entered the active use at the end of 70 years of the XX century. According to the methodological principle of constructivism in philosophy, psychology, sociology (J. Kelly, J. Piaget, A. Schutz, K. Gergen, P. Berger, T. Lukman, V.S. Stepin, U. Maturana, F. Varela, E.fon Glasersfeld) knowledge is not contained directly in the object (in objective reality) and cannot be ejected from it 
during the movement from the relative to the absolute truth, and it is built (constructed) by the knowing subject in form of various models, which can be as interchangeable and mutually complementary (quote by Petrenko, 2010)

Currently, a constructivist approach is recognized as one of the most influential approaches in social sciences. There is a diversity of constructivist approaches. V.A. Janchuk, citing J. Portera, gives the following approaches: analysis of reasoning (Atkinson, Hertrage), discourse analysis (Potter, Wetherell), ethnomethodology (Button), ethogenics (Harre), feminist studies (Radke, Stam), post-structuralism (Culler, Holway), postmodern political studies (Derian, Shapiro), rhetorics (Billig), reflexive ethnography (Clifford Markus), sociology of scientific knowledge (Latour Woolgar), socio-cultural psychology (Wertsch), symbolic interactionism (Hewitt) (quote by Janchuk, 2005).

A.M. Ulanovskii distinguishes three branches in constructivist paradigm:

1. Constructivism (in narrow sense): language, culture and ways of categorizing the world. This direction includes: genetic epistemology of J. Piaget; personal constructivism of J. Kelly; categorization theory by J. Bruner; phenomenological sociology of knowledge by P. Berger and T. Luckmann; theory of social systems by N. Luhmann. Theories that, in their own way, anticipated the constructivism, include the phenomenological sociology of A. Schutz, symbolic interactionism of J. Mead, as well as cultural-historical psychology by L.S. Vygotsky.

2. Radical Constructivism. This group of theories is formed by communication constructivism of P. Vattslavik, radical constructivism of E. von Glasersfeld, epistemology of isolation by K.fon Förster, theory of autopoietic structures by U. Maturana and F. Varela; neurobiological constructivism by G. Roth.

3. Social constructivism (K. Gergen, R. Harre, J.. Shotter). Related to this direction are the discursive psychology of J. Potter and M. Uezerell; narrative psychology of T. Sarbin and the late J. Bruner; theory of the dialogic "I" by G. Hermans (Ulanovskii, 2009).

Despite the variety of approaches, developing in the paradigm of constructivism, domestic and foreign psychologists point provisions that combine all these approaches:

1. Constructivist approach accepts scientific knowledge as instrumentally valuable, seeing means of improvement of various objects of human life and social institutions in it.

2. Constructivism supports various theories and methodologies that enable a systematic and consistent way to explore an individual and society.

3. Constructivists are in position of anti-fundamentalism, which implies accepting the historical and cultural locality, contextuality and situativity of any truths formulated by us. Their beliefs are based on the idea of pluralism of truth and many possible definitions, theories, models, methods of representation of reality.

4. Constructivists claim that the foundation of our knowledge should not to be found in the "objective world", but in language, culture, social relations, norms and conventions adopted in a particular community. From a constructivist position, the truth or any agreement that is a valid knowledge, is occurring from relationship between members of a particular concerned community.

5. Speaking of the function of language, constructivists emphasize the constitutive, performative, transformative, metaphorical language functions. Language not only represents the world, but selects, emphasizes, suppresses, and organizes various aspects of our experience and perception of the world (Ulanovskii, 2006).

6. Constructivists (approach in social construction of V. F. Guidano, G. A. Liotti) are considering the process of development while taking into account the interaction of cognitive growth and "emotional differentiation," with the development of "emotional schemes" used in assimilating a life experience of an individual (Janchuk, 2005) .

7. Constructivism denies knowledge, representations, etc. that are acquired passively. They are studying the ability of individuals for action, creation of new systems of social representation, self-management of their lives and other. According to Kelly: "Not always individuals can accept the environment, but they can design it again and again in different ways" (Gerstenmaier \& Mandl, 2000).

The essence of the theory of constructivism is the idea that knowledge is not transmitted directly from one person to another. Knowledge is being actively built in thought processes of students. According to von Glasersfeld, in all circumstances knowledge is constructed according to individual thought processes of a subject, and is adapted to subjective experience of a person (von Glasersfeld, 2000).

Reliance on these and other positions of constructivist approaches in a great extent will help to build an effective program to help migrants in social psychological adaptation to a new environment, in formation of social 
competence, positive mental representations and vitality. It is also important to use constructivist approach in training migrants, as one of aspects of adaptation program. Extensive experience in this area is gained in Germany, where in framework of intercultural pedagogy migrants are studying the language, improving professional skills, being retrained, participating in career guidance programs, forming and developing interpersonal communication competences (Spung, 2012).

\section{Conclusion}

Thus, the social psychological adaptation of migrants is a complex, multi-faceted and long-term process. Its success depends on many factors, and mainly on formation of the ability to actively change personality traits, skills, self-change, self-correction and self-development.

The effectiveness of the constructivist approach to providing various kinds of assistance to migrants in solving problems is related, in our opinion, to the fact that it:

- focuses on building the knowledge, skills, competencies, minimizing the resources used to adapt to the new conditions of life;

- allows to teach migrants to construct knowledge, skills and other elements of their livelihoods themselves, to operate with them as with forms of solutions. A man does not receive knowledge and skills in finished form, but learns to construct within the context of his own life and activities;

- contributes to the formation of viability of migrants, their positive adaptation through creation of new systems of social representations, changing mental maps, environmental loads, composing the man's picture

\section{References} of the world and determines his social behavior and individual way of construction of social reality.

American Psychological Association. (2002). APA guidelines on multicultural education, training, research, practice, and organizational change for psychologists. Retrieved from http://www.apa.org/pi/oema/ resources/policy/multicultural-guidelines.aspx

Aroian, K. J. (1990). A model of psychological adaptation to migration and resettlement. Nursing Research, 39, 5-10. http://dx.doi.org/10.1097/00006199-199001000-00002

Bauer, E. A. (2012). Scientific and practical bases of psycho-pedagogical support of adaptation of adolescent migrants. Nizhny Novgorod, 2012.

Berry, J. W. (2001). A psychology of immigration. Journal of Social Issues, 57, 615-631. http://dx.doi.org/10.1111/0022-4537.00231

Cakir, S. G., \& Guneri, O. Y. (2011). Exploring the factors contributing to empowerment of Turkish migrant women in the UK. International Journal of Psychology, 46(3), 223-233. http://dx.doi.org/10.1080/0020 7594.2010 .532800

Gerstenmaier, J., Mandl, H. (2000). Konstruktivistische Ansätze in der Psychologie. Forschungsbericht \#123. April 2000. Ludvis-Maximilians - Universitat.

Groenewold, G., de Bruijn, B., \& Bilsborrow, R. (2012). Psychosocial Factors of Migration: Adaptation and Application of the Health Belief Model. International Migration, 50(6), 1468-1485. http://dx.doi.org/10.1111/j.1468-2435.2012.00781.x

Janchuk, V. A. (2005). Introduction to modern social psychology: Studies manual for schools. MN: ACAP.

Konstantinov, V. V. (2012a). Adaptive process of migrants and their psychological characteristics (based on materials of the Volga Federal District). Scientific Library CyberLeninka. Retrieved from http://cyberleninka.ru/article/n/adaptatsionnyy-protsess-u-migrantov-i-ih-psihologicheskie-harakteristiki-namaterialah-privolzhskogo-federalnogo-okruga\#ixzz3AC5qN4es

Konstantinov, V. V. (2012b). Determination of the specificity of adaptation process of migrants by their psychological characteristics (based on materials of the Middle Volga). News of Penza State Pedagogical University named after B.G. Belinsky. Social Sciences, 28, 1249-1256.

Kruglanski, W. A., \& Webster, M. D. (1996). A motivated gatekeeper of our minds: Need for Closure effects on interpersonal and group processes. In M. R. Sorrentino, \& E. T. Higgins (Eds.), Handbook of Motivation and Cognition: Foundations of Social Behavior (Vol. 3, pp. 333-368). New York: Guilford.

Maydell-Stevens, E., Masgoret, A. M., \& Ward, T. (2007). Psychological and socoiocultural adaptation among Russian-speaking immigrants in New Zealand. Social Policy Journal of New Zealand, 30, 178-198.

Perkins, D. D., Palmer, N. A., \& García-Ramírez, M. (2011). Psychosocial Studies of Migration and Community. 
Psychosocial Intervention, 20(3), 237-242. http://dx.doi.org/10.5093/in2011v20n3a1

Perrin, S. (2012). What is an "appropriate" migrant? Impact of the adoption of meritocratic world views by potential newcomers on their perceived ability to integrate into a Western society. European Journal of Social Psychology, 42, 263-268. http://dx.doi.org/10.1002/ejsp.1844

Petrenko, V. F. (2010). Constructivist paradigm in the humanities. Methodology and History of Psychology, 5(3), 3-12.

Rogoff, B. (2003). The cultural nature of human development. New York, NY: Oxford University Press.

Shweder, R. A., \& Sullivan, M. A. (1993). Cultural psychology: Who needs it? Annual Review of Psychology, 44, 497-523. http://dx.doi.org/10.1146/annurev.ps.44.020193.002433

Soldatova, G. U., \& Shaygerova, L. A. (1994). From Citizen to Refugee: Values and motives of Russians of near abroad. Values and symbols of national identity in conditions of a changing society. M., 120-128.

Soldatova, G. U., \& Shaygerova, L. A. (2002). Man in extreme conditions. Psychology of adaptation of forced migrants. Retrieved from http//www.ebiblioteka.ru/browse/doc/4285987

Spung, A. (2012). Migration bewegt die weiterbilding tntwichlunf, trends und perspektiven in wissenschaft und praxis. Retrieved from http:// www.de-bonn.de/doks/2012

Ulanovskii, A. M. (2006). Qualitative methodology and constructivist orientation in psychology. Questions of psychology, 3, 27-37.

Ulanovskii, A. M. (2009). Constructivism, radical constructivism, social constructivism: The world as an interpretation. Questions of psychology, 2, 35-45.

von Glasersfeld, E. (2000). Problem of constructivism. In L. P. Steffe, \& P. W. Thompson (Eds.), Radical constructivism in action building on the pioneering work of Ernst von Glasersfeld (pp. 105-133). London: Routledge Falmer.

White, G. (2010). Moral discourse and the rhetoric of emotion. In R. LeVine (Ed.), Psychological anthropology: $A$ reader in self in culture. Oxford, UK: Blackwell.

\section{Copyrights}

Copyright for this article is retained by the author(s), with first publication rights granted to the journal.

This is an open-access article distributed under the terms and conditions of the Creative Commons Attribution license (http://creativecommons.org/licenses/by/3.0/). 